\title{
Efeito da Densidade e da Distância de CaRuRU-de-Mancha e Amendoim-Bravo Na Cultura do FeiJoeiro ${ }^{1}$
}

\author{
Effect of the Density and Distance of Slender Amaranth and Milkweed on the Common Bean \\ (Phaseolus vulgaris)
}

\author{
BARROSO, A.A.M. ${ }^{2}$, YAMAUTI, M.S. ${ }^{3}$, NEPOMUCENO, M.P. ${ }^{4}$ e ALVES, P.L.C.A. ${ }^{5}$
}

\begin{abstract}
RESUMO - O objetivo deste trabalho foi avaliar a interferência causada pelo caruru-demancha (Amaranthus viridis) e amendoim-bravo (Euphorbia heterophylla), em função das densidades e distâncias, no feijoeiro (Phaseolus vulgaris) cultivar Pérola. Como recipientes, foram utilizadas caixas de cimento-amianto, com capacidade para 50 litros, preenchidas com LatossoloVermelho-Escuro. As mudas foram formadas em bandejas de 128 células preenchidas com substrato hortícola; quando as plântulas atingiram o estádio V2, foram transplantadas para as caixas, sendo as de feijoeiro numa linha central, reproduzindo a semeadura em campo, e as das plantas daninhas nas densidades de 8,16 e 32 plantas $\mathrm{m}^{-2}$, distanciadas de 0,12 e $24 \mathrm{~cm}$ das plantas de feijão e igualmente entre si. $\mathrm{O}$ experimento foi conduzido no delineamento experimental de blocos casualizados, com os tratamentos dispostos em esquema fatorial $3 \times 3+2 \mathrm{~T}$, com quatro repetições, constituindo as parcelas experimentais. Foram avaliadas características de crescimento e de produtividade da cultura e das plantas daninhas. Os dados obtidos foram submetidos à análise de variância pelo teste $\mathrm{F}$, e as médias, comparadas pelo teste de Tukey. Observou-se que as plantas daninhas obtiveram maior desenvolvimento quando em maior distância da cultura. O caruru-de-mancha causou reduções no número de vagens e na produtividade estimada do feijoeiro. Para o caruru-de-mancha, o aumento da densidade só causou redução na produtividade da cultura quando as plantas estavam distanciadas em pelo menos $12 \mathrm{~cm}$. A $0 \mathrm{~cm}$, o feijoeiro tornou-se mais competitivo e não sofreu interferência das plantas daninhas, independentemente da densidade destas.
\end{abstract}

Palavras-chave: planta daninha, competição, Phaseolus vulgaris.

\begin{abstract}
The aim of this study was to evaluate the interference caused by Slender amaranth (Amaranthus viridis) and Milkweed (Euphorbia heterophylla) at different densities and distances in the common bean (Phaseolus vulgaris) cv. Pérola. The experiment was carried out using asbestos cement boxes, with 50 liters of capacity, filled with dark red Latosol. Seeds were put to germinate in a board of 128 cells filled with horticultural substratum. When the seedlings reached the V2 stage, they were transplanted to the boxes at densities of 8, 16, and 32 plant $\mathrm{m}^{-2}$, distanced 0, 12, and $24 \mathrm{~cm}$ from the bean plants and equally among themselves. Growth and yield characteristics of the plants and weeds were evaluated. The data obtained were submitted to analysis of variance using the F test and the means were compared by the Tukey test. Weeds were found to present a greater development when far from the culture. Slender amaranth caused reductions in the number of pods and in the estimated yield of the bean plants. Increase in density only intensified the competition and reduction in crop yield when the bean plants were distant at least $12 \mathrm{~cm}$, in the slender amaranth case. At $0 \mathrm{~cm}$, the bean plants became more competitive and did not suffer competition from the weeds, regardless of their density.
\end{abstract}

Keywords: weed, competition, Phaseolus vulgaris.

1 Recebido para publicação em 15.4.2011 e aprovado em 28.9.2011.

2 Graduando em Agronomia, Faculdade de Ciências Agrárias e Veterinárias, Universidade Estadual Paulista, FCAV/UNESP, Via de acesso Prof. Paulo Donato Castellane, s/n, 14884-900 Jaboticabal-SP, Bolsista Fapesp, <arthuragro07@hotmail.com>; ${ }^{3}$ Eng - -Agr ${ }^{\text {. }}$, Doutoranda em Agronomia do Programa de Pós-Graduação em Produção Vegetal, FCAV/UNESP, Jaboticabal-SP, Bolsista Fapesp, <micheliyamauti@yahoo.com.br>; ${ }^{4}$ Engâ-Agra ${ }^{-}$, Doutora em Agronomia, Programa de Pós-Graduação em Produção Vegetal, FCAV/UNESP, Jaboticabal-SP, <mariluce_n@hotmail.com>; ${ }^{5}$ Professor Adjunto, Dep. de Biologia Aplicada à Agropecuária, FCAV/UNESP, Jaboticabal-SP, <plalves@fcav.unesp.br>.

Planta Daninha, Viçosa-MG, v. 30, n. 1, p. 47-53, 2012 


\section{INTRODUCÃO}

Apesar da pouca produtividade em nível nacional, que gira em torno de $850 \mathrm{~kg} \mathrm{ha}^{-1}$, o feijoeiro vem sendo explorado em uma diversidade de sistemas de produção em diferentes agroecossistemas, obtendo-se produtividades superiores a $3.000 \mathrm{~kg} \mathrm{ha}^{-1}$, principalmente nos cultivos irrigados, associado à utilização em maior quantidade de insumos agrícolas e em função da disponibilidade de cultivares que possuem potencial produtivo acima de $4.000 \mathrm{~kg} \mathrm{ha}^{-1}$ (Farinelli \& Lemos, 2010). Devido à maior aceitação pelos consumidores do Estado de São Paulo, há predominância do plantio de cultivares de feijoeiro comum com tipo de grão Carioca (Embrapa, 2011).

Entre as várias causas para a baixa produtividade nacional, podem-se citar vários fatores, entre os quais a interferência das plantas daninhas (Teixeira et al., 2000), que pode causar redução de 15 a $80 \%$ na produtividade de grãos (Salgado et al., 2007; Barroso et al., 2010).

A competição é a principal interferência direta das plantas daninhas nas culturas agrícolas e pode ocorrer por nutrientes minerais, luz, água e/ou espaço (Pitelli, 1987). O grau de interferência entre as plantas cultivadas e as plantas daninhas depende de fatores relacionados à comunidade infestante (composição específica, densidade e distribuição) e à própria cultura (espécie ou cultivar, espaçamento entre sulcos e densidade de semeadura). Depende também da duração do período de convivência, da época em que esse período ocorre, que é acondicionada pelas condições edáficas e climáticas e pelos tratos culturais (Pitelli, 1985).

Analisando a cultura do feijão, constatase que, em média, 20 a $30 \%$ do seu custo total de produção refere-se ao controle de plantas daninhas (Silva et al., 2000). Por esse motivo, estudos mais elaborados sobre a interferência das plantas daninhas são fundamentais na tentativa de reduzir o uso de herbicidas e, consequentemente, os custos e o impacto ambiental negativo provocado pelo emprego destes.

Barroso et al. (2010), estudando a competitividade de várias espécies de plantas daninhas sobre os feijoeiros Carioca e Rubi, em duas épocas de semeadura, verificaram que a espécie Amaranthus viridis foi a mais agressiva entre todas, causando prejuízos no crescimento e desenvolvimento da cultura, com reduções de até $80 \%$ na produtividade final do feijoeiro. Para Euphorbia heterophylla, Sangakkara \& Bandaranayake (2004) verificaram alta adaptação da planta quando em convivência com o feijoeiro, apresentando um sistema radicular mais expandido, possibilitando assim melhor aproveitamento dos recursos do solo, demonstrando maior competitividade.

A hipótese do trabalho é de que duas espécies de plantas daninhas - em três densidades e mantidas a três distâncias da linha de plantio do feijoeiro - afetarão de modo diferenciado o crescimento e a produtividade da cultura. Assim, este trabalho teve por objetivo avaliar a competitividade e a interferência causada pelo caruru-de-mancha (Amaranthus viridis) e amendoim-bravo (Euphorbia heterophylla), em diferentes densidades e distâncias, sobre a produtividade do feijoeiro Pérola.

\section{MATERIAL E MÉTODOS}

O experimento foi conduzido em caixas de cimento-amianto com capacidade para 50 litros $(0,62 \times 0,62 \times 0,26 \mathrm{~m})$, preenchidas com solo coletado na camada arável de um Latossolo Vermelho-Escuro e mantidas a céu aberto, no periodo de junho a outubro de 2009 , para o caruru, e de novembro de 2009 a fevereiro de 2010, para o amendoim-bravo. Após o enchimento, coletou-se uma amostra composta do substrato, que foi submetida à análise química e física (Tabela 1). Mediante os resultados da análise de solo, não foram necessárias adubação e calagem.

O cultivar de feijão estudado foi o Peróla, grão do tipo Carioca, com ciclo de 95 dias, porte semiereto, peso médio de 100 sementes de 27 gramas e potencial de produtividade de $4.000 \mathrm{~kg} \mathrm{ha}^{-1}$, resistente ao mosaico-comum (Embrapa, 2011).

As mudas de feijão cultivar Peróla, carurude-mancha e amendoim-bravo foram formadas em bandejas de poliestireno expandido de 128 células preenchidas com substrato hortícola (Plantmax HT). As sementes de caruru e amendoim-bravo foram coletadas em áreas agrícolas infestadas. 
Tabela 1 - Caracterização física e química e classificação textural da amostra de solo utilizada no experimento

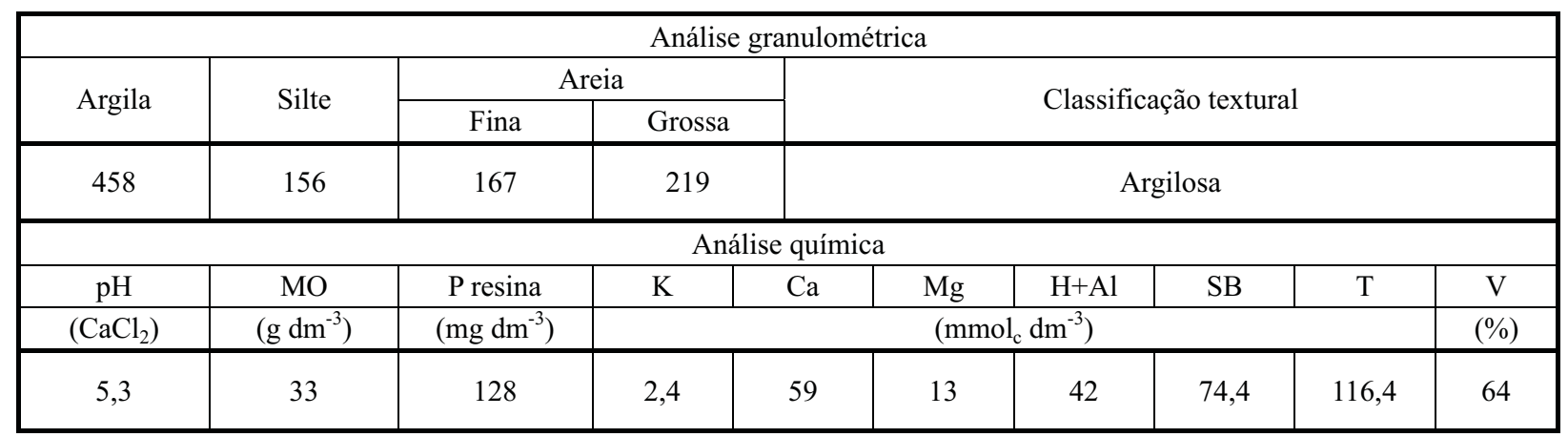

Todas as mudas foram transplantadas quando estavam no estágio V2. Seis mudas de feijão foram transplantadas na linha central das caixas. Os tratamentos experimentais consistiram da combinação de três densidades de caruru ou amendoim-bravo $(8,16$ e 32 plantas $\mathrm{m}^{-2}$ ) transplantadas em três distâncias $(0,12$ e $24 \mathrm{~cm})$ das plantas de feijão. Além disso, foram mantidos uma testemunha sem a presença da planta daninha e um tratamento com a presença de caruru ou amendoim-bravo na ausência de plantas de feijoeiro.

Dessa forma, o experimento constou de 11 tratamentos, sendo três densidades e três distâncias, com duas testemunhas adicionais. O delineamento experimental utilizado foi o de blocos casualizados, com os tratamentos dispostos em esquema fatorial $3 \times 3+2 \mathrm{~T}$, em quatro repetições.

No decorrer do período experimental, além da irrigação periódica das plantas (sempre que visualmente necessária), foram adotadas todas as práticas necessárias para a manutenção das boas condições sanitárias das plantas, realizando aplicações preventivas e curativas de inseticidas e fungicidas. As plantas daninhas que emergiram espontaneamente nas parcelas experimentais foram arrancadas manualmente.

Por ocasião da colheita, realizada cerca de 90 dias após a semeadura do feijoeiro, nas plantas daninhas foi determinada a massa seca da parte aérea e, nas plantas de feijão, determinaram-se características produtivas: número de vagens por planta, massa fresca das vagens, massa seca dos grãos, massa de 50 grãos, grãos por vagem e produtividade estimada do feijoeiro A produtividade média de cada tratamento foi estimada segundo Fancelli \& Dourado Neto (2007), pela seguinte fórmula:

$$
R=\frac{P \cdot V p \cdot G v \cdot M}{1.000}
$$

em que $P$ é a população (166.000 plantas ha-1); $V p$, o número médio de vagens por planta; $G v$, número médio de grãos por vagem; e $M$, a massa média por unidade de grão ou semente. A massa seca foi obtida depois do material seco em uma estufa de circulação forçada de ar, na temperatura de $70{ }^{\circ} \mathrm{C}$, por no mínimo 96 horas.

Os dados obtidos foram submetidos à análise de variância pelo teste $\mathrm{F}$, e as médias, comparadas pelo teste de Tukey a $5 \%$ de probabilidade, utilizando-se o programa Estat./ UNESP.

\section{RESULTADOS E DISCUSSÃO}

\section{Caruru}

$\mathrm{Na}$ análise das características produtivas do feijoeiro em convivência com caruru, verificou-se que as densidades da planta daninha proporcionaram efeitos semelhantes entre si para todas as variáveis analisadas, porém houve diferença entre os tratamentos testados e a testemunha somente para a variável número de vagens por planta (Tabela 2). Quando as plantas se encontravam distanciadas em $24 \mathrm{~cm}$, a interferência foi maior do que a presença da planta daninha na mesma linha de semeadura da cultura $(0 \mathrm{~cm})$. Quando as plantas foram semeadas em 
Tabela 2 - Número de vagens por planta, massa fresca das vagens, massa seca dos grãos, massa de 50 grãos, grãos por vagem e produtividade estimada do feijoeiro Pérola em função da densidade e distância de plantas de caruru. Jaboticabal-SP, 2010

\begin{tabular}{|c|c|c|c|c|c|c|}
\hline & $\begin{array}{c}\text { № de vagem por } \\
\text { planta }\end{array}$ & $\begin{array}{l}\text { Massa fresca de } \\
\text { vagens }(\mathrm{g})\end{array}$ & $\begin{array}{l}\text { Massa seca de } \\
\text { grãos (g) }\end{array}$ & $\begin{array}{l}\text { Massa de } 50 \\
\text { grãos }(\mathrm{g})\end{array}$ & $\begin{array}{l}\text { Grãos por } \\
\text { vagem }\end{array}$ & $\begin{array}{c}\text { Produtividade } \\
\text { estimada } \\
\left(\mathrm{kg} \mathrm{ha}^{-1}\right)\end{array}$ \\
\hline \multicolumn{7}{|c|}{ Densidade (De) plantas $\mathrm{m}^{-2}$} \\
\hline 8 & $10,19 \mathrm{a}$ & $151,43 \mathrm{a}$ & $109,48 \mathrm{a}$ & $13,59 \mathrm{a}$ & $2,38 \mathrm{a}$ & $3.889,77 \mathrm{a}$ \\
\hline 16 & $10,38 \mathrm{a}$ & $148,26 \mathrm{a}$ & $112,01 \mathrm{a}$ & $13,85 \mathrm{a}$ & $2,50 \mathrm{a}$ & $4.097,62 \mathrm{a}$ \\
\hline 32 & $10,07 \mathrm{a}$ & $148,79 \mathrm{a}$ & $106,49 \mathrm{a}$ & $13,78 \mathrm{a}$ & $2,40 \mathrm{a}$ & $3.857,03 \mathrm{a}$ \\
\hline \multicolumn{7}{|c|}{ Distância (Di) de plantio das plantas de caruru $(\mathrm{cm})$} \\
\hline 0 & $10,52 \mathrm{a}$ & $147,94 \mathrm{a}$ & $111,21 \mathrm{a}$ & $13,45 \mathrm{a}$ & $2,47 \mathrm{a}$ & $4.108,15 \mathrm{ab}$ \\
\hline 12 & $10,24 \mathrm{ab}$ & $158,63 \mathrm{a}$ & $113,61 \mathrm{a}$ & $14,31 \mathrm{a}$ & $2,38 \mathrm{a}$ & $4.120,99 \mathrm{a}$ \\
\hline 24 & $9,88 \mathrm{~b}$ & $141,90 \mathrm{a}$ & $103,16 \mathrm{a}$ & $13,47 \mathrm{a}$ & $2,44 \mathrm{a}$ & $3.615,29 \mathrm{~b}$ \\
\hline Testemunha & 11,14 & 166,70 & 117,54 & 12,86 & 2,38 & $4.387,83$ \\
\hline $\mathrm{F}_{\mathrm{TxF}}$ & $8,41 * *$ & $1,44^{\mathrm{NS}}$ & $1,00^{\mathrm{NS}}$ & $2,85^{\mathrm{NS}}$ & $0,23^{\mathrm{NS}}$ & $2,81^{\mathrm{NS}}$ \\
\hline $\mathrm{F}_{\mathrm{De}}$ & $0,77^{\mathrm{NS}}$ & $0,05^{\mathrm{NS}}$ & $0,38^{\mathrm{NS}}$ & $0,21 \mathrm{NS}$ & $1,39^{\mathrm{NS}}$ & $0,82^{\mathrm{NS}}$ \\
\hline $\mathrm{F}_{\mathrm{Di}}$ & $3,45 *$ & $1,16^{\mathrm{NS}^{-}}$ & $1,48^{\mathrm{NS}}$ & $2,90 \mathrm{NS}$ & $0,72^{\mathrm{NS}}$ & $4,02^{*}$ \\
\hline$F_{\text {DexDi }}$ & $1,64^{\mathrm{NS}}$ & $0,66^{\mathrm{NS}^{-}}$ & $0,38^{\mathrm{NS}}$ & $0,32^{\mathrm{NS}}$ & $0,43^{\mathrm{NS}}$ & $1,46^{\mathrm{NS}}$ \\
\hline DMS & 0,61 & 27,55 & 15,78 & 1,00 & 0,19 & 504,36 \\
\hline $\mathrm{CV}(\%)$ & 5,87 & 17,99 & 14,15 & 7,26 & 7,86 & 12,48 \\
\hline
\end{tabular}

Médias seguidas de mesma letra não diferem entre si pelo teste de Tuley; *, ** significativo a 5 e $1 \%$ de probabilidade, respectivamente. № não significativo.

uma mesma linha, ambas as raizes estavam justapostas, fato esse que cria uma intensa competição por recursos do meio (Green et al., 1988), indicando assim que o feijoeiro pode ter sido mais competitivo que a planta daninha nessas condições de competição.

Devido à redução no número de vagens, a produtividade estimada também foi prejudicada. Para $24 \mathrm{~cm}$ de distância entre plantas, a produção foi menor em comparação à obtida a $12 \mathrm{~cm}$ e semelhante à obtida a $0 \mathrm{~cm}$. Neste caso, o efeito das distâncias de 0 e $12 \mathrm{~cm}$ foi semelhante, independentemente da população de plantas (Tabela 2). Esses resultados corroboram os de Silva et al. (2010), que verificaram que as plantas de $A$. viridis causaram maior interferência na absorção de nutrientes de tomateiro quando distanciadas a mais de 10 cm. Já Byrd Jr. \& Coble (1991) observaram que a distância de $17 \mathrm{~cm}$ entre plantas de algodão e capim-colchão (Digitaria sanguinalis) foi a que mais prejudicou o desenvolvimento e a produção da cultura; e Hernandez et al. (2007) observaram maior interferência de maria-pretinha (Solanum americanum) em tomateiro quando a distância entre a cultura e a daninha era de $12 \mathrm{~cm}$ entre as plantas.
Para as plantas de caruru, nota-se que todos os tratamentos com convivência com o feijoeiro causaram redução no acúmulo de matéria seca se comparados à testemunha, com reduções de até $90 \%$. Houve maior desenvolvimento das plantas mais distantes do feijoeiro (12 e 24 cm); o maior acúmulo de massa seca ocorreu quando estavam presentes 32 plantas $\mathrm{m}^{-2}$; o menor, com 8 plantas $\mathrm{m}^{-2}$; e a densidade de 16 plantas $\mathrm{m}^{-2}$ foi semelhante às demais (Tabela 3). Resultados semelhantes de acumulo de matéria seca foram obtidos por Marcolini et al. (2010), em que houve maior acumulo nas maiores densidades.

A principal determinante da eficiência na captura dos recursos do solo são o tamanho, à distribuição em relação à disponibilidade dos recursos e a atividade dos órgãos de fixação (Scott \& Geddes, 1979). Nesse sentido, segundo Rizzardi et al. (2001), o tamanho do sistema radicular normalmente sofre redução quando a planta cresce em competição com plantas daninhas vizinhas. Conforme Carvalho et al. (2008), por ser a planta de feijoeiro mais competitiva do que a $A$. viridis, seu estabelecimento inicial torna-se mais rápido do que o da planta daninha - nesse caso, inibindo o 
rápido desenvolvimento desta quando ambas estavam presentes na mesma linha. Verificou-se que, quando em maiores distâncias, as plantas de caruru obtiveram maior desenvolvimento, o que acarretou problemas no desenvolvimento do feijoeiro. Esse fato pode ser observado também pelo menor acúmulo de massa seca das plantas de caruru nas menores distâncias das plantas de feijão (Tabela 3).

Seibert \& Pearce (1993) observaram que o comprimento radicular, na emergência, foi maior para espécies com sementes grandes; já para espécies oriundas de sementes pequenas, como o caruru, esses autores observaram reduzido diâmetro de raiz durante o período inicial de crescimento. Dessa forma, inferese que o rápido estabelecimento feijoeiro em condições adequadas ao seu crescimento ocupou grande parte do espaço disponivel às raizes e limitou o desenvolvimento do caruru. Com o aumento da distância dessas plantas, observou-se que as plantas de caruru com espaço livre para o seu crescimento inicial e com abundância de nutrientes apresentaram crescimento mais rápido que o do feijoeiro, o qual, segundo Cobucci et al. (1996), tem

Tabela 3 - Massa seca acumulada por plantas de caruru, em função da densidade e distância de plantas, em convivência com o feijoeiro Pérola. Jaboticabal-SP, 2010

\begin{tabular}{|c|c|}
\hline Tratamento & Massa seca caruru $(\mathrm{g})$ \\
\hline \multicolumn{2}{|c|}{ Densidade (De) plantas. $\mathrm{m}^{-2}$} \\
\hline 8 & $7,78 \mathrm{~b}$ \\
\hline 16 & $13,16 \mathrm{ab}$ \\
\hline 32 & $19,67 \mathrm{a}$ \\
\hline \multicolumn{2}{|c|}{ Distância (Di) de plantio das plantas de caruru $(\mathrm{cm})$} \\
\hline 0 & $7,48 \mathrm{~b}$ \\
\hline 12 & $14,81 \mathrm{ab}$ \\
\hline 24 & $19,31 \mathrm{a}$ \\
\hline Testemunha & 82,24 \\
\hline $\mathrm{F}_{\mathrm{TxF}}$ & $159,61 * *$ \\
\hline $\mathrm{F}_{\mathrm{De}}$ & $4,00 *$ \\
\hline $\mathrm{F}_{\mathrm{Di}}$ & $3,95 *$ \\
\hline$F_{\text {DexDi }}$ & $0,56^{\mathrm{NS}}$ \\
\hline DMS & 10,44 \\
\hline $\mathrm{CV}(\%)$ & 50,55 \\
\hline
\end{tabular}

Médias seguidas de mesma letra não diferem entre si pelo teste de Tukey. *, ** significativo a 5 e $1 \%$ de probabilidade, respectivamente. NS não significativo. crescimento inicial lento, possibilitando assim a ocorrência de interferência de modo que a produção do feijoeiro fosse afetada. A interferência, nesse caso, pode ter ocorrido tanto pelo sombreamento do feijoeiro pelo caruru como pela competição entre as raízes, seja por água ou nutrientes ou até mesmo espaço. Após determinado tempo de crescimento, as raizes passam a ocupar o mesmo espaço e competir pelos mesmos recursos. O tempo que isso levou pode coincidir com o período crítico da absorção de nutrientes pelo feijoeiro e maior acúmulo de matéria seca, que ocorre entre 45 e 48 dias, segundo Vieira (2008). Pode-se, portanto, afirmar que, nesse caso, a competição com plantas de caruru é mais prejudicial quando ocorre nesse período e para plantas já estabelecidas.

Quanto à massa fresca de vagens, não foram observadas diferenças significativas; o mesmo ocorreu para massa seca dos grãos, massa de 50 grãos e número de grãos por vagem (Tabela 2).

Assim, a produtividade do feijoeiro foi afetada negativamente pelo convivio com plantas de caruru, chegando a reduções de $26 \%$, assim como observado por Bensch et al. (2003). No tocante às plantas de caruru, o aumento da densidade nas distâncias de 12 e $24 \mathrm{~cm}$ aumentou a pressão exercida na cultura, reduzindo a produtividade do feijoeiro; contudo, a $0 \mathrm{~cm}$, o aumento na densidade de plantas de caruru não causou interferência na cultura.

\section{Amendoim-bravo}

Para todas as características produtivas avaliadas, as densidades e a distância das plantas de amendoim-bravo causaram efeitos semelhantes entre si. Os valores obtidos não diferiram entre si estatisticamente. Para número de vagens por planta, massa fresca das vagens, massa seca dos grãos e massa de 50 grãos, a interferência não foi suficiente para acarretar reduções em niveis estatísticos (Tabela 4). Somente nas variáveis grãos por vagem e produtividade estimada os valores obtidos na convivência com as plantas de amendoim-bravo diferiram dos obtidos na testemunha (Tabela 4). Avaliando essas duas variáveis, pode-se afirmar que o convivio com as plantas daninhas nos diferentes tratamentos causaram redução 
Tabela 4 - Número de vagens por planta, massa fresca das vagens, massa seca dos grãos, massa de 50 grãos, grãos por vagem e produtividade estimada do feijoeiro Pérolaem função da densidade e distância de planta de amendoim- bravo. Jaboticabal-SP, 2010

\begin{tabular}{|c|c|c|c|c|c|c|}
\hline & $\begin{array}{c}\mathrm{N}^{\mathrm{o}} \text { de vagem por } \\
\text { planta }\end{array}$ & $\begin{array}{c}\text { Massa fresca de } \\
\text { vagens }(\mathrm{g})\end{array}$ & $\begin{array}{l}\text { Massa seca de } \\
\text { grãos }(\mathrm{g})\end{array}$ & $\begin{array}{c}\text { Massa de } 50 \\
\text { grãos }(\mathrm{g})\end{array}$ & $\begin{array}{l}\text { Grãos por } \\
\text { vagem }\end{array}$ & $\begin{array}{c}\text { Produtividade } \\
\text { estimada } \\
\left(\mathrm{kg} \mathrm{ha}^{-1}\right)\end{array}$ \\
\hline \multicolumn{7}{|c|}{ Densidade (De) plantas $\mathrm{m}^{-2}$} \\
\hline 8 & $2,98 \mathrm{a}$ & $57,21 \mathrm{a}$ & $39,13 \mathrm{a}$ & $15,03 \mathrm{a}$ & $2,22 \mathrm{a}$ & $1.554,25 \mathrm{a}$ \\
\hline 16 & $3,16 \mathrm{a}$ & $59,73 \mathrm{a}$ & $40,69 \mathrm{a}$ & $15,28 \mathrm{a}$ & $2,19 \mathrm{a}$ & $1.748,75 \mathrm{a}$ \\
\hline 32 & $2,97 \mathrm{a}$ & $51,78 \mathrm{a}$ & $38,31 \mathrm{a}$ & $14,69 \mathrm{a}$ & $2,24 \mathrm{a}$ & $1.577,91 \mathrm{a}$ \\
\hline \multicolumn{7}{|c|}{ Distância (Di) de plantio das plantas de amendoim-bravo $(\mathrm{cm})$} \\
\hline 0 & $3,02 \mathrm{a}$ & $58,76 \mathrm{a}$ & $40,87 \mathrm{a}$ & $15,52 \mathrm{a}$ & $2,24 \mathrm{a}$ & $1.711,08 \mathrm{a}$ \\
\hline 12 & $3,10 \mathrm{a}$ & $55,31 \mathrm{a}$ & $40,23 \mathrm{a}$ & $14,62 \mathrm{a}$ & $2,17 \mathrm{a}$ & $1.573,16 \mathrm{a}$ \\
\hline 24 & $3,00 \mathrm{a}$ & $54,65 \mathrm{a}$ & $37,03 \mathrm{a}$ & $14,86 \mathrm{a}$ & $2,24 \mathrm{a}$ & $1.596,66 \mathrm{a}$ \\
\hline Testemunha & 3,15 & 66,67 & 47,88 & 16,43 & 2,40 & $2.304,25$ \\
\hline $\mathrm{F}_{\mathrm{TxF}}$ & $0,42^{\mathrm{NS}}$ & $1,51 \mathrm{NS}$ & $2,28^{\mathrm{NS}}$ & $3,69^{\mathrm{NS}}$ & $6,05^{*}$ & $8,23^{* *}$ \\
\hline $\mathrm{F}_{\mathrm{De}}$ & $1,38^{\mathrm{NS}}$ & $0,76^{\mathrm{NS}}$ & $0,15^{\mathrm{NS}}$ & $0,52 \mathrm{NS}$ & $0,40 \mathrm{NS}$ & $0,67^{\mathrm{NS}}$ \\
\hline $\mathrm{F}_{\mathrm{Di}}$ & $0,29^{\mathrm{NS}}$ & $0,233^{\mathrm{NS}}$ & $0,45^{\mathrm{NS}}$ & $1,30^{\mathrm{NS}}$ & $1,00^{\mathrm{NS}}$ & $0,33^{\mathrm{NS}}$ \\
\hline $\mathrm{F}_{\text {DexDi }}$ & $0,74^{\mathrm{NS}}$ & 0,21 & $0,59^{\mathrm{NS}}$ & $0,89^{\mathrm{NS}}$ & $1,61 \mathrm{NS}$ & $0,74^{\mathrm{NS}}$ \\
\hline DMS & 0,32 & 16,30 & 10,81 & 1,43 & 0,14 & 453,55 \\
\hline $\mathrm{CV}(\%)$ & 10,57 & 28,10 & 26,55 & 9,34 & 6,38 & 26,43 \\
\hline
\end{tabular}

Médias seguidas de mesma letra não diferem entre si pelo teste de Tukey. ${ }^{*},{ }^{* *}$ significativo a 5 e $1 \%$ de probabilidade, respectivamente. Ns não significativo.

na produtividade de $20 \%$, com relação à testemunha livre de competição.

Tabela 5 - Massa seca acumulada por plantas de amendoimbravo, em função da densidade e distribuição de plantas, em convivência com o feijoeiro Pérola. Jaboticabal-SP, 2010

\begin{tabular}{|c|c|}
\hline Tratamento & Massa seca amendoim-bravo (g) \\
\hline \multicolumn{2}{|c|}{ Densidade $(\mathrm{De})$ plantas $\mathrm{m}^{-2}$} \\
\hline 8 & $17,17 \mathrm{a}$ \\
\hline 16 & $20,68 \mathrm{a}$ \\
\hline 32 & $24,24 \mathrm{a}$ \\
\hline \multicolumn{2}{|c|}{$\begin{array}{l}\text { Distância (Di) de plantio das plantas de amendoim-bravo } \\
(\mathrm{cm})\end{array}$} \\
\hline 0 & $13,44 \mathrm{~b}$ \\
\hline 12 & $24,52 \mathrm{a}$ \\
\hline 24 & $24,13 \mathrm{a}$ \\
\hline Testemunha & 32,81 \\
\hline $\mathrm{F}_{\mathrm{TxF}}$ & $7,19^{*}$ \\
\hline $\bar{F}_{\mathrm{De}}$ & $2,044^{\mathrm{NS}}$ \\
\hline $\mathrm{F}_{\mathrm{Di}}$ & $6,46 * *$ \\
\hline$F_{\text {DexDi }}$ & $2,87^{*}$ \\
\hline $\mathrm{CV}(\%)$ & 39,12 \\
\hline
\end{tabular}

Médias seguidas de mesma letra não diferem entre si pelo teste de Tukey. *, ** significativo a 5 e $1 \%$ de probabilidade, respectivamente. ${ }^{\text {Ns }}$ não significativo.
Em relação ao acúmulo de massa seca por plantas de amendoim-bravo, houve interação entre os efeitos da densidade e os da distribuição das plantas (Tabela 5). Observase que, para 8 plantas $\mathrm{m}^{-2}$, a distância de $12 \mathrm{e}$ $24 \mathrm{~cm}$ possibilitou maior desenvolvimento, comparada à distância de $0 \mathrm{~cm}$ (Tabela 6). $\mathrm{O}$ mesmo ocorreu para 32 plantas $\mathrm{m}^{-2}$; para 16 plantas $\mathrm{m}^{-2}$, não se observaram diferenças significativas em relação no acúmulo de massa seca para diferentes distâncias (Tabela 6).

Tabela 6 - Desdobramento do efeito da densidade e da distância sobre a massa seca acumulada por plantas de amendoimbravo em convivência com o feijoeiro Pérola. JaboticabalSP, 2010

\begin{tabular}{|c|c|c|c|}
\hline \multirow{2}{*}{$\begin{array}{c}\text { Densidade de } \\
\text { amendoim-bravo } \\
\left(\text { plantas } \mathrm{m}^{-2}\right) \text { - De }\end{array}$} & \multicolumn{3}{|c|}{$\begin{array}{c}\text { Distância de amendoim-bravo }(\mathrm{cm}) \text { - } \\
\text { Di }\end{array}$} \\
\hline & 0 & 12 & 24 \\
\hline 8 & $9,31 \mathrm{bA}$ & $13,83 \mathrm{ab} \mathrm{B}$ & 28,36 a A \\
\hline 16 & 17,06 a A & 24,87 a $\mathrm{AB}$ & 20,10 a $\mathrm{A}$ \\
\hline 32 & $13,95 \mathrm{~b} \mathrm{~A}$ & 34,86 a $\mathrm{A}$ & $23,92 \mathrm{ab} A$ \\
\hline DMS para Di dentro de De & \multicolumn{3}{|c|}{15,03} \\
\hline DMS para De dentro de Di & \multicolumn{3}{|c|}{15,03} \\
\hline
\end{tabular}

Letras minúsculas no sentido das linhas comparam a massa seca das diferentes distâncias dentro de cada densidade de planta; letras maiúsculas no sentido da coluna comparam as densidades das plantas dentro de cada distância. 
Para 0 e $24 \mathrm{~cm}$, as diferentes densidades as plantas acumularam quantidades semelhantes de massa seca; entretanto, em baixa densidade, ou seja, em 8 plantas $\mathrm{m}^{2}$, o acúmulo por planta foi maior. Para $12 \mathrm{~cm}$, o maior acúmulo ocorreu para 32 plantas por $\mathrm{m}^{-2}$. $\mathrm{O}$ efeito da densidade de 16 plantas $\mathrm{m}^{-2}$ assemelhou-se ao das densidades de 32 e 8 plantas $\mathrm{m}^{-2}$ (Tabela 6).

Assim, nas condições do experimento, verificou-se que o caruru foi mais agressivo ao feijoeiro do que o amendoim-bravo, porém ambos afetaram negativamente sua produtividade.

\section{LITERATURA CITADA}

BARROSO, A. A. M.; YAMAUTI, M. S.; ALVES, P. L. C. A. Interferência entre espécies de planta daninha e duas cultivares de feijoeiro em duas épocas de semeadura.

Bragantia, v. 69, n. 3, p. 609-616, 2010.

BENSCH, C.N.; HORAK, M.J.; PETERSON, D. Interference of redroot pigweed (Amaranthus retroflexus), Palmer amaranth (A. palmerri) and common waterhemp (A. rudis) in soybean. Weed Sci., v. 51, n. 1, p. 37-43, 2003.

BYRD, JR, J. D.; COBLE, H. D. Interference of selected weeds in cotton (Gossypium hirsutum). Weed Technol., v. 5, n.2, p. 263-269, 1991.

CARVALHO, S. J. P.; LÓPEZ-OVEJERO, R. F.; CHRISTOFFOLETI, P. J. Crescimento e desenvolvimento de cinco espécies de plantas daninhas do gênero Amaranthus. Bragantia, v. 67, n.1, p. 317-326, 2008.

COBUCCI, T.; FERREIRA, F. A.; SILVA, A. A. Controle de plantas daninhas. In: ARAUJO, R. S. et al. (Coord.). Cultura do feijoeiro comum no Brasil. Piracicaba: POTAFOS, 1996. p. 433-464.

EMBRAPA. Empresa Brasileira de Pesquisa Agropecuaria. Cultivares. Disponivel em: <http://www.cnpaf.embrapa.br/ feijao/perola.htm>.Acesso em: 22 mar. 2010.

FANCELLI, A. L.; DOURADO-NETO, D. Produção de feijão. Piracicaba: ESALQ/USP, Departamento de Agricultura, 2007. p. 46.

FARINELLI, R.; LEMOS, L. B. Características agronômicas de genotipos de feijoeiro cultivados nas épocas da seca e das águas. Bragantia, v. 69, n. 2, p. 361-366, 2010.

GREEN, J. D.; MURRAY, D. S.; STONE, J. F. Soil water relations of silverleaf nightshade (Solanum elaeagnifolium) with cotton (Gossypium hirsutum). Weed Sci., v. 36, n. 6, p. 740-746, 1988.
HERNANDEZ, D. D. et al. Períodos de interferência de Maria-pretinha sobre o tomateiro industrial. Hortic. Bras., v. 24, n. 1, p. 199-202, 2007.

MARCOLINI, W. et al. Interferencia de caruru-de-mancha sobre características de crescimento e produção da beterraba. Planta Daninha, v. 28, n. 1, p. 41-46, 2010.

PITELLI, R. A. Interferência de plantas daninhas em culturas agrícolas. Inf. Agropec., v. 11, n. 129, p. 16-27, 1985.

PITELLI, R. A. Competição e controle das plantas daninhas em áreas agrícolas. Série Técn. IPEF, v. 4, n. 12, p. 1-24, 1987.

RIZZARDI, M. A. et al. Competição por recursos do solo entre ervas daninhas e culturas. Ci. Rural, v. 31, n. 4, p. 707-714, 2001.

SALGADO, T. P. et al. Interferência das plantas daninhas no feijoeiro carioca. Planta Daninha, v. 25, n. 3, p. 443-448, 2007.

SANGAKKARA, U. R.; BANDARANAYAKE, P. S. R. D. Morphological and physiological determinants of the competitive ability of Euphorbia heterophylla when grown with Phaseolus beans. J. Plant Dis. Protec., v. 1, n.2, p. 245-251, 2004.

SCOTT, H. D.; GEDDES, R. D. Plant water stress of soybean (Glycine max) and common cocklebur (Xanthium pensylvanicum): a comparison under field conditions. Weed Sci., v. 27, n. 3, p. 285-289, 1979.

SEIBERT, A. C.; PEARCE, R. B. Growth analysis of weed and crop species with reference to seed weight. Weed Sci., v. 41, n. 1, p. 52-56, 1993.

SILVA, A. A. et al. Controle de plantas daninhas. Brasília, DF: ABEAS, 2000. 260 p.

SILVA, B. P. B. et al. Interferência de caruru-de-mancha, maria-pretinha, picão-preto e tiririca em tomateiro industrial. Bragantia, v. 69, n. 2, p. 313-318, 2010.

TEIXEIRA, I. R. et al. Resposta do feijoeiro (Phaseolus vulgaris L. cv. Pérola) a diferentes densidades de semeadura e doses de nitrogênio. Ci. Agrotecnol., v. 24, n. 2, p. 399-408, 2000 .

VIEIRA, N. M. B. et al. Altura de planta e acúmulo de matéria seca do feijoeiro cvs. BRS MG Talismã e Ouro Negro em plantio direto e convencional. Ci. Agrotecnol., v. 32, n.3, p. 1687-1693, 2008. 